\title{
Nitric Oxide Production and Perivascular Tyrosine Nitration in Brain after Carbon Monoxide Poisoning in the Rat
}

\author{
Harry Ischiropoulos, ${ }^{\star \ddagger}$ Michael F. Beers, ${ }^{\star}$ S. Tsuyoshi Ohnishi, ${ }^{\S}$ Donald Fisher, ${ }^{\star}$ Sarah E. Garner, ${ }^{\star}$ and Stephen R. Thom ${ }^{\star \uparrow}$ \\ *Institute for Environmental Medicine, ${ }^{\ddagger}$ Department of Biochemistry and Biophysics, and "Emergency Medicine, School of Medicine, \\ University of Pennsylvania, Philadelphia, Pennsylvania, 19104; and ${ }^{\S}$ Philadelphia Biomedical Research Institute, King of Prussia, \\ Pennsylvania 19406
}

\begin{abstract}
Nitric oxide is a short-lived free radical and physiological mediator which has the potential to cause cytotoxicity. Studies were conducted to investigate whether nitric oxide, and the potent oxidant peroxynitrite, were generated in brain during experimental carbon monoxide $(\mathrm{CO})$ poisoning in the rat. Nitric oxide production was documented by electron paramagnetic resonance spectroscopy, and found to be increased by ninefold immediately after $\mathrm{CO}$ poisoning. Evidence that peroxynitrite was generated was sought by looking for nitrotyrosine in the brains of $\mathrm{CO}$-poisoned rats. Nitrotyrosine was found deposited in vascular walls, and also diffusely throughout the parenchyma in immunocytochemical studies. The affinity and specificity of an anti-nitrotyrosine antibody was investigated and a solid phase immunoradiochemical assay was developed to quantify nitrotyrosine in brain homogenates. A $\mathbf{1 0}$-fold increase in nitrotyrosine was found in the brains of $\mathrm{CO}$-poisoned rats. Platelets were involved with production of nitrotyrosine in the early phase of exposure to CO. However, nitrotyrosine formation and leukocyte sequestration were not decreased in thrombocytopenic rats poisoned with $\mathrm{CO}$ according to the standard model. When rats were pre-treated with the nitric oxide synthase inhibitor, L-nitroarginine methyl ester, formation of both nitric oxide and nitrotyrosine in response to $\mathrm{CO}$ poisoning were abolished, as well as leukocyte sequestration in the microvasculature, endothelial xanthine dehydrogenase conversion to xanthine oxidase, and brain lipid peroxidation. We conclude that perivascular reactions mediated by peroxynitrite are important in the cascade of events which lead to brain oxidative stress in $\mathrm{CO}$ poisoning. (J. Clin. Invest. 1996. 97:2260-2267.) Key words: peroxynitrite • nitric oxide - nitrotyrosine - electron paramagnetic resonance $\cdot$ oxidative injury
\end{abstract}

\section{Introduction}

Experimental evidence implicates oxidative stress as a major cause of tissue injury in a variety of human disorders and ex-

Address correspondence to Stephen R. Thom, M.D., Ph.D., University of Pennsylvania, Institute for Environmental Medicine, 1 John Morgan Building, 3620 Hamilton Walk, Philadelphia, PA. 191046068. Phone: 215-898-9095; FAX: 215-898-0868.

Received for publication 15 November 1995 and accepted in revised form 9 February 1996.

J. Clin. Invest.

(C) The American Society for Clinical Investigation, Inc.

0021-9738/96/05/2260/08 \$2.00

Volume 97, Number 10, May 1996, 2260-2267 perimental models of disease. Oxidative stress is the result of excessive production of reactive species that overwhelm the cellular antioxidant capacity, leading to inactivation of key cellular functions and ultimately to cell death. Although most studies have concentrated on the contribution of oxygenderived reactive species such as superoxide, recent reports have also described excessive production of nitric oxide in association with tissue injury (1). Nitric oxide-related tissue injury may be at least partially due to peroxynitrite, a relatively long-lived, strong oxidant that is generated by the near diffusion-limited reaction between nitric oxide and superoxide (2).

The mechanism of brain injury after carbon monoxide $(\mathrm{CO})^{1}$ poisoning is incompletely understood. Several recent clinical reports have suggested that the primary site of injury may be the vasculature, and that focal pathology, a hallmark of $\mathrm{CO}$ poisoning, may arise secondary to hemorrhagic necrosis $(3,4)$. We hypothesized that peroxynitrite may be produced in animals during $\mathrm{CO}$ poisoning because exposure to $\mathrm{CO}$ has been found to enhance the rates of production of both nitric oxide, and partially reduced oxygen species $(5,6)$. Platelets liberate large amounts of nitric oxide coincident with exposure to $\mathrm{CO}$ (5). Exposure to $\mathrm{CO}$ at concentrations sufficient to disturb cardiovascular function can also perturb mitochondrial electron transport, and increase the production of partially reduced oxygen species (6). Oxidative stress, documented as brain lipid peroxidation, occurs in rats when the exposure to CO terminates with events that include systemic hypotension, cerebral hypoperfusion and impaired mitochondrial function (7-10).

Peroxynitrite is capable of oxidizing lipids, thiols, deoxyribose, and a number of other small organic molecules $(11,12)$. A major product from the reaction of peroxynitrite with proteins is nitrotyrosine (13). Using antibodies that specifically recognize nitrotyrosine, extensive protein nitration has been detected in human coronary artery atherosclerotic lesions (14), in acute lung injury $(15,16)$, and in endotoxemia $(17,18)$. In this paper we have investigated the production of nitric oxide in brain and the potential for using nitrotyrosine as a marker of peroxynitrite-mediated oxidative stress. We have examined the affinity and specificity of a polyclonal anti-nitrotyrosine antibody and we have quantified the amount of nitrotyrosine in brain tissue using a solid phase immunoradiochemical assay.

\section{Methods}

Animals and reagents. Wistar male rats (Charles River Laboratories, Wilmington, MA) weighing 200-290 grams were fed a standard diet and water ad libitum. Reagents were purchased from Sigma Chemical Corp. (St. Louis, MO) unless otherwise specified.

1. Abbreviations used in this paper: $\mathrm{CO}$, carbon monoxide; DETC, diethyldithiocarbamate; L-NAME, L-nitroarginine methyl ester. 
Exposure of rats to carbon monoxide. Exposure to $\mathrm{CO}$ followed our model which has been described in detail in several previous publications (7-10). In brief, rats were placed in a seven-liter Plexiglas chamber into which a small volume of pure $\mathrm{CO}$ was injected to achieve a concentration of $1000 \mathrm{ppm}$. A mixture of $1000 \mathrm{ppm} \mathrm{CO}$ in air was flushed through at a rate of 8 to 12 liters per minute for 40 min, at which time the gas was switched to $3000 \mathrm{ppm} \mathrm{CO}$ in air and another $\mathrm{CO}$ bolus was added. In day-to-day experiments, usually two out of three rats lost consciousness in this environment within 20 min and were then removed from the chamber to breath room air. Rats that did not spontaneously lose consciousness after exposure to 3000 ppm for $20 \mathrm{~min}$ were rendered unconscious with a $60 \mathrm{cc}$ bolus of pure $\mathrm{CO}$. We have found that unconsciousness is a reliable outward manifestation of systemic hypotension and cerebral hypoperfusion whether it occurs with exposure to $3000 \mathrm{ppm} \mathrm{CO}$ or with the bolus of pure $\mathrm{CO}(8,10)$. In some studies rats were exposed to only $1000 \mathrm{ppm}$ $\mathrm{CO}$ for 40 or $60 \mathrm{~min}$, or to $3000 \mathrm{ppm} \mathrm{CO}$ for 1 to $2 \mathrm{~min}$ plus a bolus of pure $\mathrm{CO}$ to cause unconsciousness. In other studies rats were made thrombocytopenic by an intraperitoneal injection of $1.5 \mathrm{ml} / \mathrm{kg}$ rat plasma-adsorbed rabbit anti-rat platelet antiserum (Inter-cell Technologies, Hopewell, NJ) given $2 \mathrm{~h}$ before exposure to $\mathrm{CO}$. Neutropenia was caused by an intraperitoneal injection of $4 \mathrm{ml} / \mathrm{kg}$ anti-neutrophil antiserum (Inter-cell Technologies, Hopewell, NJ) administered $24 \mathrm{~h}$ before study. L-nitroarginine methyl ester (L-NAME, $1 \mathrm{mg} / \mathrm{kg}$ s.q.) was injected $2 \mathrm{~h}$ before $\mathrm{CO}$ exposure. At the end of $\mathrm{CO}$ exposures, rats were killed by decapitation within $8 \mathrm{~min}$. The brain was removed from the skull and homogenized with a Polytron blender using $10 \mathrm{ml}$ TBS. Homogenates were diluted 1:500 (vol/vol) with TBS for analysis by solid phase radioimmunoassay. Biochemical assays of xanthine dehydrogenase, xanthine oxidase and conjugated dienes were performed on brain homogenates by following methods described in previous publications (7-9). Microvessels were isolated, and myeloperoxidase was assayed, as previously described (7).

Electron paramagnetic resonance measurement of nitric oxide. Rats were exposed to $\mathrm{CO}$ according to our standard model. After exposure to $1000 \mathrm{ppm} \mathrm{CO}$ for $20 \mathrm{~min}$, rats were briefly removed and injected subcutaneously with diethyldithiocarbamate (DETC) $(500 \mathrm{mg} / \mathrm{kg}$ ) and, at a second site, with a ferrous sulfate $(50 \mathrm{mg} / \mathrm{kg})$-sodium citrate $(250 \mathrm{mg} / \mathrm{kg})$ mixture (19). The rats were replaced in the CO environment, exposed to $1000 \mathrm{ppm} \mathrm{CO}$ for an additional $20 \mathrm{~min}$ and then to $3000 \mathrm{ppm} \mathrm{CO}$ for $20 \mathrm{~min}$. Unconscious rats were removed from the $\mathrm{CO}$ environment, decapitated 8 min later and one cerebral hemisphere was extruded into a quartz EPR tubing (4 mm diameter). The specimen was immediately frozen in liquid nitrogen. EPR spectra were recorded using a Varian E-109 spectrometer equipped with a liquid flow system (temperature was set at $-130^{\circ} \mathrm{C}$ ). The EPR settings were: $9.22 \mathrm{GHz}$ microwave frequency, $20 \mathrm{~mW}$ microwave power, $100 \mathrm{KHz}$ modulation frequency, $0.32 \mathrm{mT}$ modulation and $0.25 \mathrm{~s}$ time constant. Two types of EPR signals are observed in the rat brain: a quartet hyperfine spectrum of $\mathrm{Cu}$-DETC and a nitric oxide-Fe-DETC spectrum which is similar to the Cu-DETC spectrum but reveals two distinct peaks at $\mathrm{g}=2.047$ and $\mathrm{g}=2.025(19,20)$. The nitric oxideFe-DETC spectrum was observed only when rats were injected with both Fe and DETC and not with either Fe or DETC alone, consistent with previous reports $(19,20)$.

Immunohistochemistry. Staining was carried out with an affinity purified polyclonal anti-nitrotyrosine antibody obtained from Dr. J.S. Beckman, University of Alabama at Birmingham. The polyclonal antibody was raised by immunizing rabbits with peroxynitrite-treated keyhole limpet hemocyanin as described previously (13). The binding characteristics of this antibody were investigated using peroxynitritemodified BSA that had been immobilized onto nitrocellulose using the 96 well Bio-Dot microfiltration unit (BioRad, Hercules, CA). Fatty acid free bovine serum albumin $(4 \mathrm{mg} / \mathrm{ml})$ was reacted with peroxynitrite in $100 \mathrm{mM}$ potassium phosphate buffer that contained $100 \mu \mathrm{M}$ of the metal chelator diethylenepentaacetic acid (DTPA), pH 7.4. Peroxynitrite was synthesized as described previously (1), or by utilizing 3-morpholinosydnonimine (SIN-1) which decomposes to release nitric oxide as well as superoxide (21). The yield of nitration was determined by measuring the absorbance at $\mathrm{pH} 11.5,\left(\epsilon_{428 \mathrm{~nm}}=4,400 \mathrm{M}^{-1}\right.$ $\left.\mathrm{cm}^{-1}\right)$.

After CO poisoning, rats were anesthetized by an intraperitoneal injection with ketamine $(73.5 \mathrm{mg} / \mathrm{kg})$ and xylazine $(1.5 \mathrm{mg} / \mathrm{kg})$. Brains were fixed in situ by infusing $4 \%$ paraformaldehyde in a $0.1 \mathrm{M}$ sodium cacodylate buffer through a catheter in the left ventricle under $50 \mathrm{~cm}$ of water pressure. The brains were removed, left in fixative for three hours, and then cryoprotected by $1 \mathrm{~h}$ incubations in 10,20, and $30 \%$ sucrose in $0.1 \mathrm{M}$ sodium cacodylate buffer. The brains were placed on OTC-coated tissue holders, covered with a thin layer of OTC, and frozen with distilled freon 22 in liquid nitrogen. Eight micron thin sections were prepared and placed onto poly-L-lysine coated slides. Before staining, slides were soaked twice for $5 \mathrm{~min}$ to remove excess fixative. When a peroxidase-based staining method was to be used, endogenous peroxidase was quenched by incubating sections with $0.3 \%$ methanolic hydrogen peroxide $(1: 25 \mathrm{vol} / \mathrm{vol} 30 \%$ hydrogen peroxide:methanol) for $20 \mathrm{~min}$. Slides were rinsed with PBS and incubated for 20 min with blocking solution (4\% fatty acid free BSA, $10 \%$ goat serum and $3 \%$ Triton X-100 in 0.1 M PBS, pH 7.2). Slides were rinsed with PBS and incubated for $1.5 \mathrm{~h}$ with either anti-nitrotyrosine polyclonal antibody at $10 \mu \mathrm{g} / \mathrm{ml}$, with antigen-competed primary antibody, with an irrelevant rabbit IgG, or with antiCD31 polyclonal antibody at $20 \mu \mathrm{g} / \mathrm{ml}$. The competed reagent for the anti-nitrotyrosine antibody was prepared by diluting the primary antibody at $10 \mu \mathrm{g} / \mathrm{ml}$ in $0.1 \mathrm{M}$ PBS that contained $10 \mathrm{mM}$ nitrotyrosine (Aldrich). Slides used for visualizing the presence of antibody on tis-

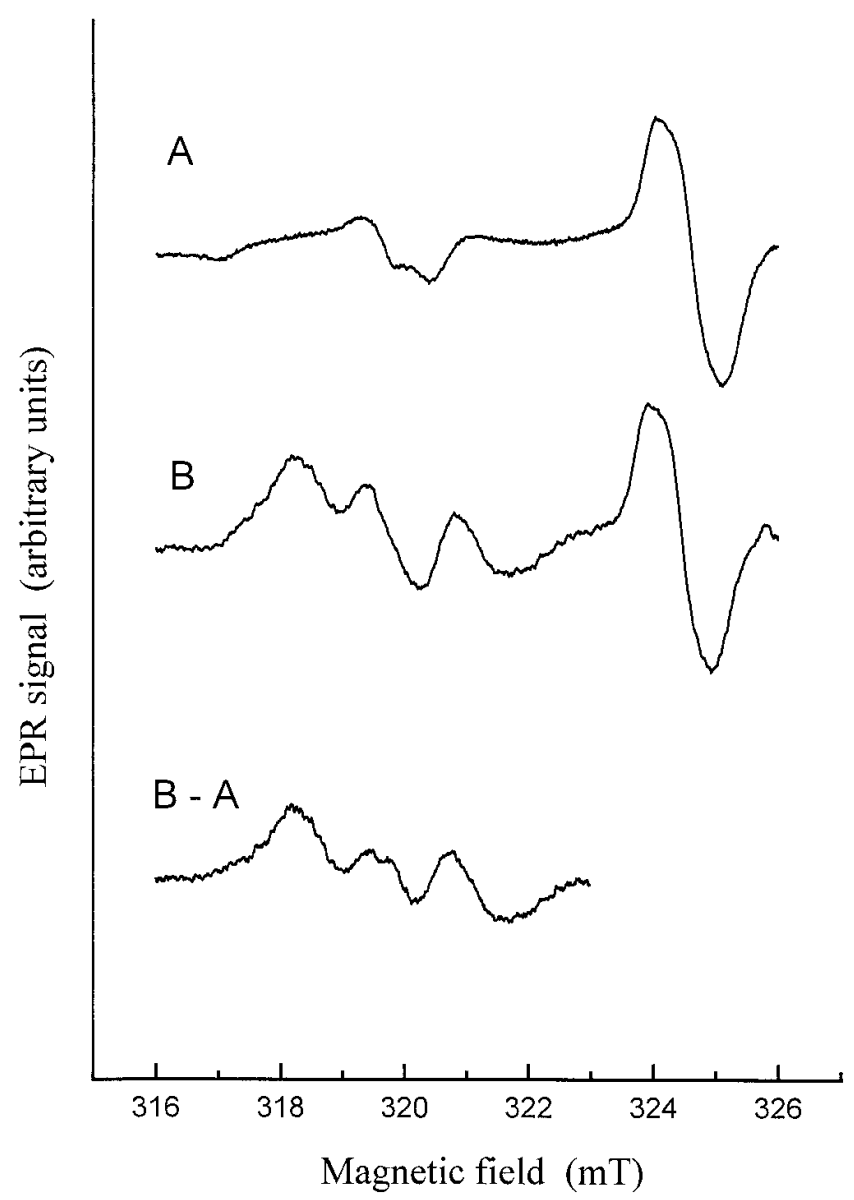

Figure 1. Electron spin resonance spectra of rat cerebral cortex from a control rat $(A)$, from a $\mathrm{CO}$ poisoned rat $(B)$ and difference spectrum $(B-A)$. 
sue sections by immunofluorescence were incubated for $1 \mathrm{~h}$ with an anti-rabbit IgG conjugated to Texas red (1:100 dilution in TBS) and examined under a Nikon Diaphot-TND epifluorescence inverted microscope. Antibody was also visualized using a peroxidase based method by following the manufacturer's instructions (Elite Vectastain Kit, Vector Labs, Burlingame, CA). Sections were stained with biotinylated anti-rabbit IgG for $30 \mathrm{~min}$, washed for $20 \mathrm{~min}$ with PBS, and incubated for $30 \mathrm{~min}$ with a solution of Avidin DH and biotinylated horseradish peroxidase. Slides were rinsed with PBS and incubated with a solution of $1.4 \mathrm{mM}$ diaminobenzidine tetrachloride and $0.3 \%$ (vol/vol) hydrogen peroxide for $3 \mathrm{~min}$, washed with water, and counterstained with Harris-modified hematoxylin.

Solid phase immunoradiochemical assay. Tissue proteins were immobilized onto nitrocellulose using the 96 well Bio-Dot microfiltration unit (BioRad, Hercules, CA). 8-12 different concentrations of peroxynitrite-modified BSA standard were also loaded in duplicate on each blot to generate a standard curve. $4-8$ concentration-dependent dilutions of the tissue protein samples were loaded in $400 \mu \mathrm{l}$ TBS. After blocking with either $2 \%$ gelatin or $5 \%$ dry milk, the nitrocellulose was incubated with the anti-nitrotyrosine antibody for $15 \mathrm{~h}$ followed by a 3 -h incubation in a solution containing a donkey antirabbit ${ }^{125} \mathrm{I}$-labeled $\mathrm{IgG}(0.1-0.2 \mathrm{mCi} / \mathrm{ml})$. The blot was extensively washed in Tween-TBS and dried. The radioactivity of each sample was measured directly by Beta scanning using an Ambis 400 imaging detector. The net counts of radioactivity (corrected for background counts from a sample blank) were obtained using the AMBIS image analysis software v4.1 and then plotted on a semi-logarithmic plot.

Reduction of nitrotyrosine with dithionite for solid phase immunoradiochemical assay. Nitrotyrosine was reduced to aminotyrosine with dithionite under alkaline conditions. The dithionite solution was made fresh daily by placing dithionite crystals in a plastic tube that had first been flushed with nitrogen and then adding deaerated buffer to dissolve the crystals. The $\mathrm{pH}$ of $1 \mathrm{ml}$ brain homogenate was adjusted to 9.0 by the addition of sodium hydroxide and a freshly prepared dithionite solution was added to a final concentration of $0.5 \mathrm{M}$ in order to reduce nitrotyrosine to aminotyrosine. Dithionite-reduced samples were prepared fresh because of the time dependent auto-oxidation of aminotyrosine back to nitrotyrosine. The radioactive counts obtained from Dot-blots of dithionite-reacted samples were subtracted from the counts of unreacted samples, and net counts were used in calculations of brain nitrotyrosine concentration.

Statistics. Statistical significance was determined by ANOVA followed by Scheffe's test (22). The level of significance was taken as $P<0.05$. Results are expressed as mean \pm SE.

\section{Results}

Detection of nitric oxide in brain after $C O$ poisoning by electron paramagnetic resonance spectroscopy (EPR). Rats were poisoned with $\mathrm{CO}$ in a manner known to cause brain oxidative injury (7-9, see Methods) and the relative concentration of nitric oxide in brains was evaluated using EPR. A triplet nitric oxide signal, characteristic for the nitric oxide-iron-DETC adduct (20), was found in the brains of rats immediately after they were poisoned with $\mathrm{CO}$ (Fig. 1). The height of this signal averaged ninefold greater than the signal found in control rats in three
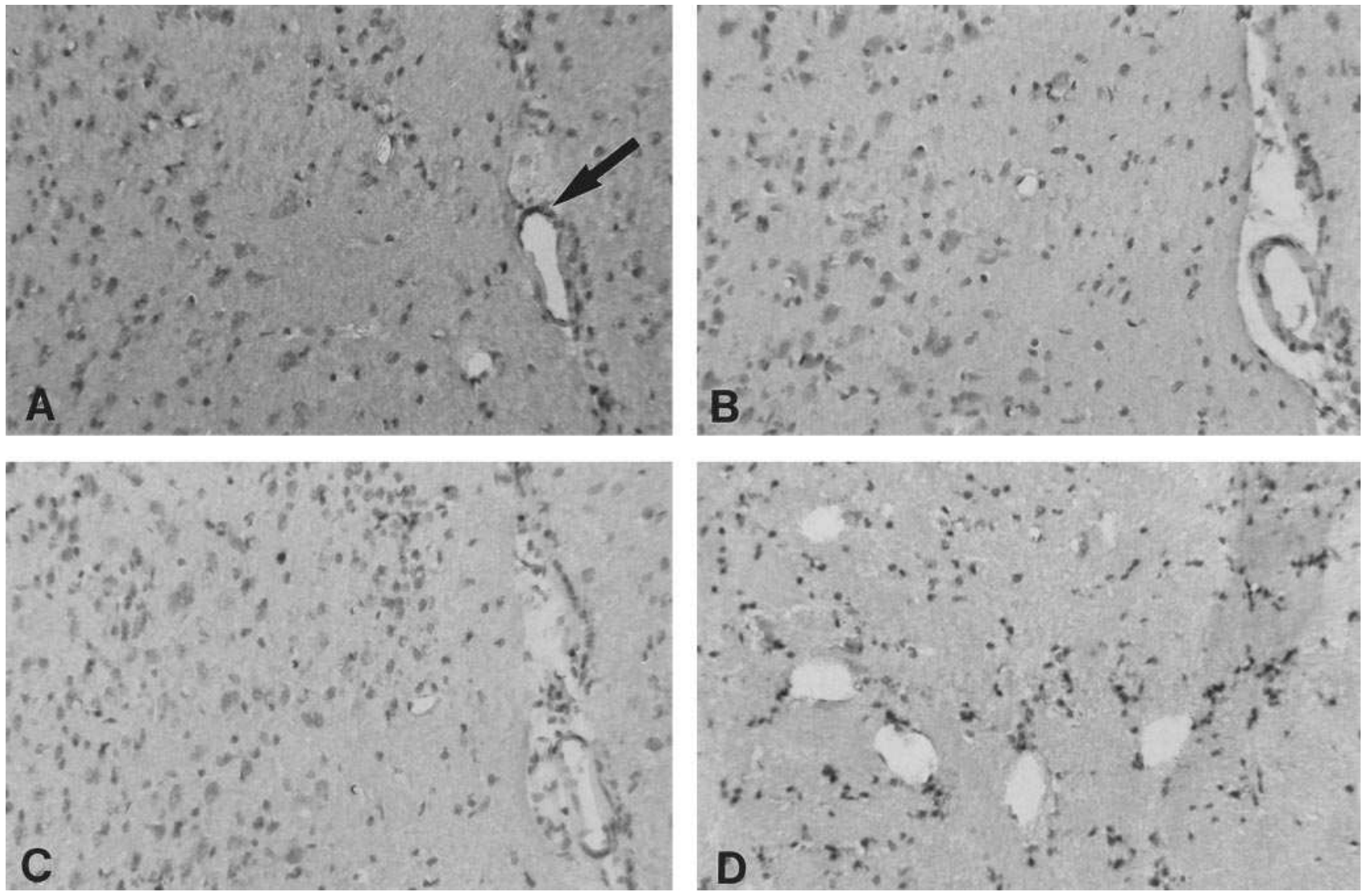

Figure 2. Photomicrographs from immunoperoxidase-stained rat cerebral cortex. $A-C$ show thin sections from a rat poisoned with CO. ( $A$ ) Section stained with anti-nitrotyrosine antibody. Positive staining is indicated by dark coloration, especially around the vessel (arrow). (B) Stained with antigen-competed anti-nitrotyrosine antibody. (C) Stained with non-specific IgG. $(D)$ A section from a control rat brain stained with antinitrotyrosine antibody. $\times 250$. 

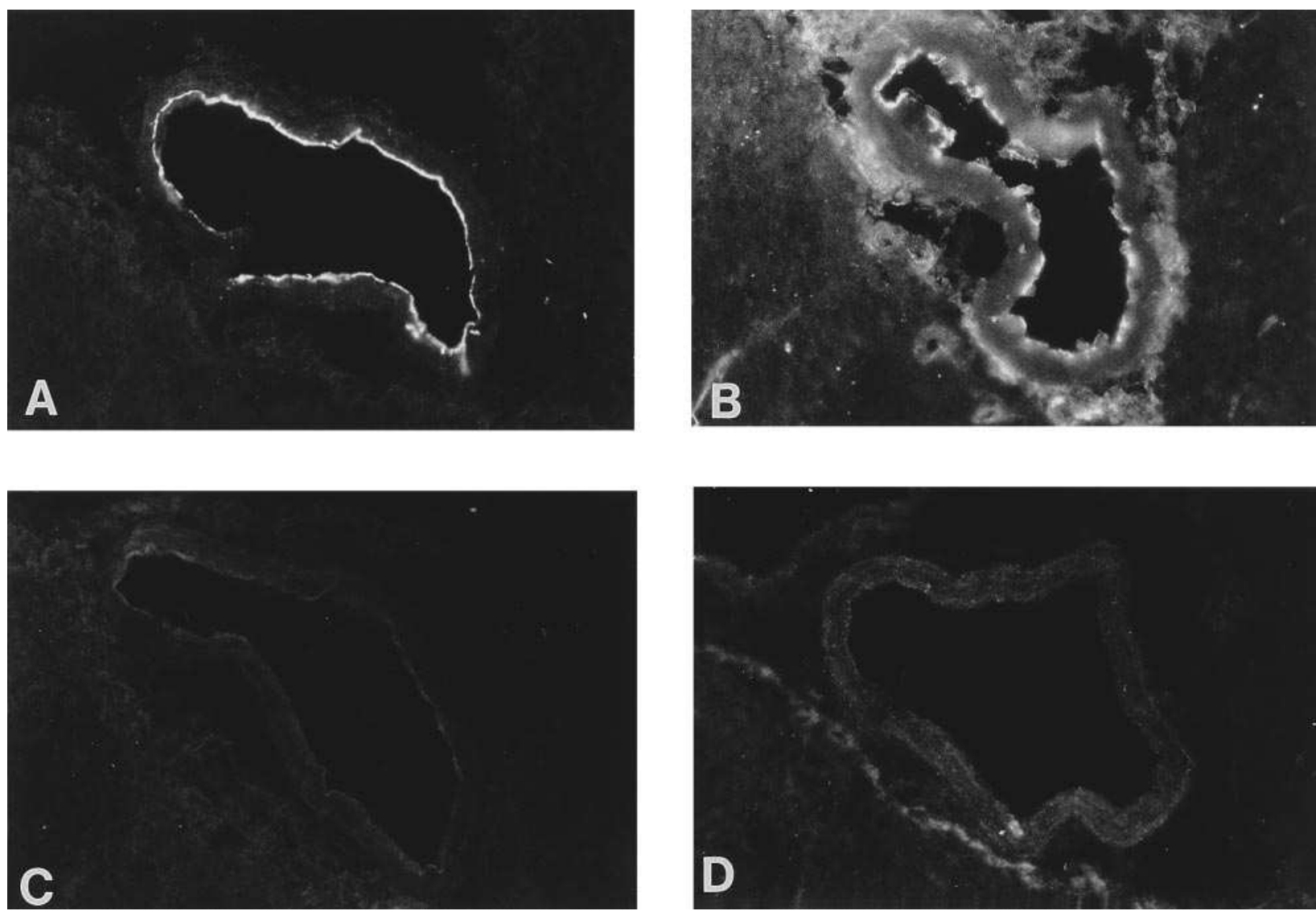

Figure 3. Immunofluorescence photomicrographs from cerebral cortex. Panels show serial thin sections from a rat poisoned with CO. $(A)$ Stained with anti-nitrotyrosine antibody. (B) Stained with anti-CD31 antibody. $(C)$ Stained with antigen-competed anti-nitrotyrosine antibody. (D) Stained with non-specific IgG. $\times 875$.

paired trials. The triplet nitric oxide signal is clearly seen in difference spectra (Fig. 1). When rats were treated before $\mathrm{CO}$ poisoning with the nitric oxide synthase inhibitor, L-NAME, the nitric oxide-Fe-DETC adduct was not found. The nitric oxide signal diminished in intensity in brains obtained $>8-10$ min after $\mathrm{CO}$ poisoning, and was not detectable in brains beyond 20 min after $\mathrm{CO}$ poisoning.

Immunocytochemical studies of brain. Brains from control and CO-poisoned rats were sectioned and stained with antinitrotyrosine antibody. A diffuse pattern of staining, with no localization to specific structures such as the basal ganglia, was present in brains from rats poisoned with $\mathrm{CO}$ (Fig. 2). Staining was not found in brains from control rats. On close examination of serial brain sections, relatively dense deposits of nitrotyrosine were frequently found in a perivascular location. While this could be appreciated to some degree with the immunoperoxidase staining, it was most clearly discerned in fluorescence micrographs (Fig. 3). One panel in Fig. 3 also shows a section stained with antibodies to CD31, or PECAM-1, which is expressed on endothelial cells and has been used to highlight vascular structures (23).

Binding characteristics of the polyclonal antibody against nitrotyrosine. In the process of developing a method to quantify tissue nitrotyrosine, we first established the binding characteristics of the polyclonal affinity purified anti-nitrotyrosine antibody. Binding by the antibody was found to be saturable and dependent on the concentration of both the antibody and antigen (Fig. 4, $A$ and $B$ ). When antibody was used at a con- centration of $2 \mu \mathrm{g} / \mathrm{ml}$, binding of nitrotyrosine increased linearly with increasing antigen concentration up to $1 \mu \mathrm{g}$ of nitrotyrosine. Using solutions of antibody $(2 \mu \mathrm{g} / \mathrm{ml})$ and $50 \mathrm{ng}$ of immobilized antigen, we determined the $\mathrm{K}_{\mathrm{i}}$ for nitrotyrosine inhibition of binding to be $2.5 \mu \mathrm{M}$ (Fig. $4 C$ ). The binding of the antibody under the same conditions was not inhibited by the presence of $10 \mathrm{mM}$ of aminotyrosine $(115 \pm 4 \%)$, phosphotyrosine $(126 \pm 3 \%)$, methyltyrosine $(141 \pm 14 \%)$ and tyrosine $(91 \pm 4 \%)$.

Nitrotyrosine quantification in brain. Nitrotyrosine formation in brain after $\mathrm{CO}$ poisoning was quantified by using the solid phase radiochemical assay (Fig. 5). A 10-fold increase in nitrotyrosine was found after $\mathrm{CO}$ poisoning and the nitrotyrosine level was not significantly different in neutropenic rats (circulating neutrophil counts $<200$ cells/ $\mu$ l blood). However, nitrotyrosine was not increased in brains from rats that had been pretreated with a competitive nitric oxide synthase inhibitor, L-NAME.

In previous studies we have found that oxidative injury in the brain depends on the pattern of $\mathrm{CO}$ poisoning (8). Whereas the standard model (see Methods) will precipitate changes including brain lipid peroxidation, exposure to just $3000 \mathrm{ppm}$ $\mathrm{CO}$ will cause a temporary drop in blood pressure that is manifested as a loss of consciousness, but lipid peroxidation does not occur $(8,10)$. Nitrotyrosine was not increased in the brains of rats exposed to $3000 \mathrm{ppm} \mathrm{CO}$ for $<2 \mathrm{~min}$ and to a pulse of pure $\mathrm{CO}$ to cause unconsciousness (Fig. 5). The mean carboxyhemoglobin level in these rats was $81 \pm 1 \%$, a level somewhat 

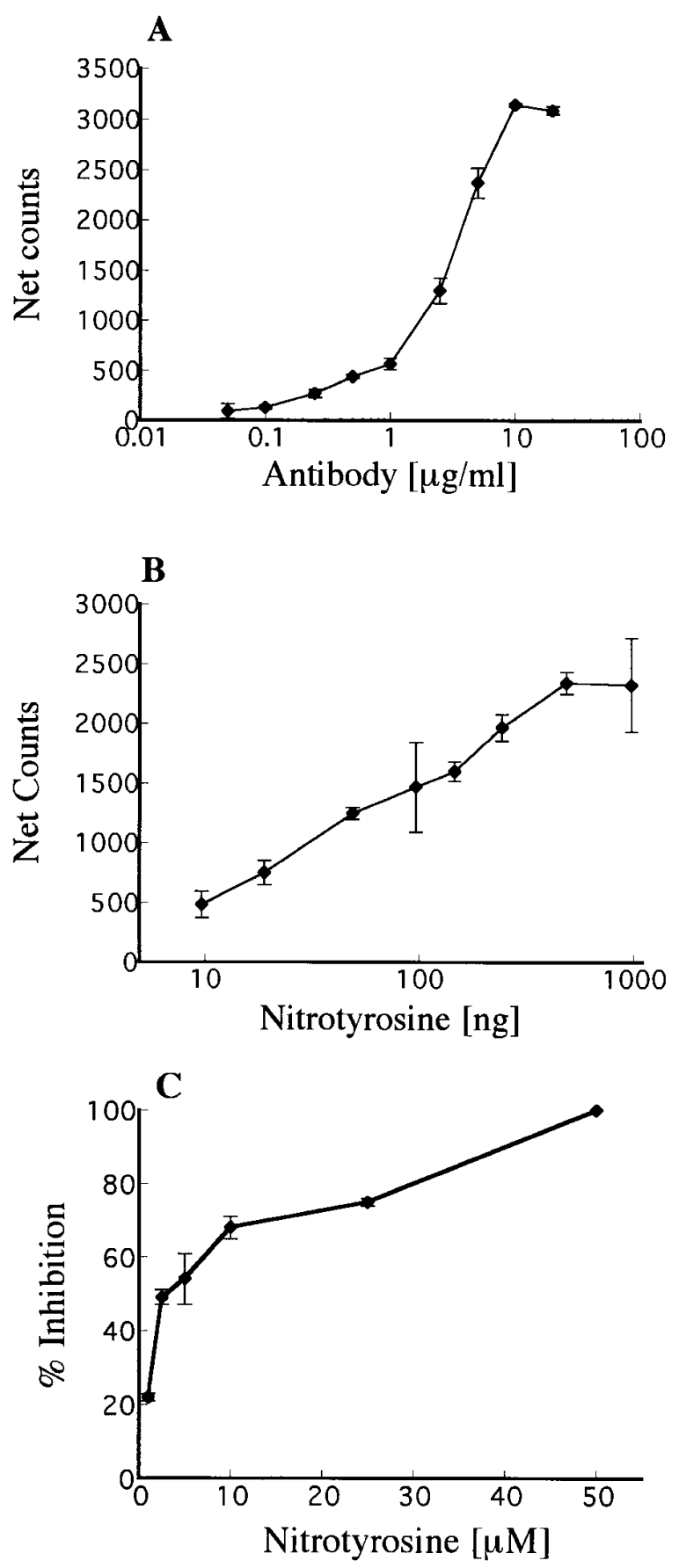

Figure 4. Characterization of the polyclonal affinity-purified antinitrotyrosine antibody. $(A)$ Antibody binding to $50 \mathrm{ng}$ of immobilized antigen (peroxynitrite-modified fatty acid free BSA). (B) Antigen concentration dependent binding of anti-nitrotyrosine antibody $(2 \mu \mathrm{g} /$ $\mathrm{ml})$. (C) Competition of antibody binding with free nitrotyrosine. Peroxynitrite-modified fatty acid free BSA containing $50 \mathrm{ng}$ of nitrotyrosine was immobilized onto nitrocellulose. Antibody solutions (2 $\mu \mathrm{g} / \mathrm{ml}$ ) were incubated for $1 \mathrm{~h}$ at room temperature with different concentrations of nitrotyrosine dissolved in PBS, $\mathrm{pH} 7.5(n=4)$. The antibody binding was visualized with the addition of ${ }^{125} \mathrm{I}$-labeled donkey anti-rabbit IgG.

higher than the carboxyhemoglobin level in rats exposed to the standard model $66 \pm 3 \%(n=8, P<0.05)$. This indicates that nitrotyrosine production was not due simply to an hypoxic stress precipitated by $\mathrm{CO}$.

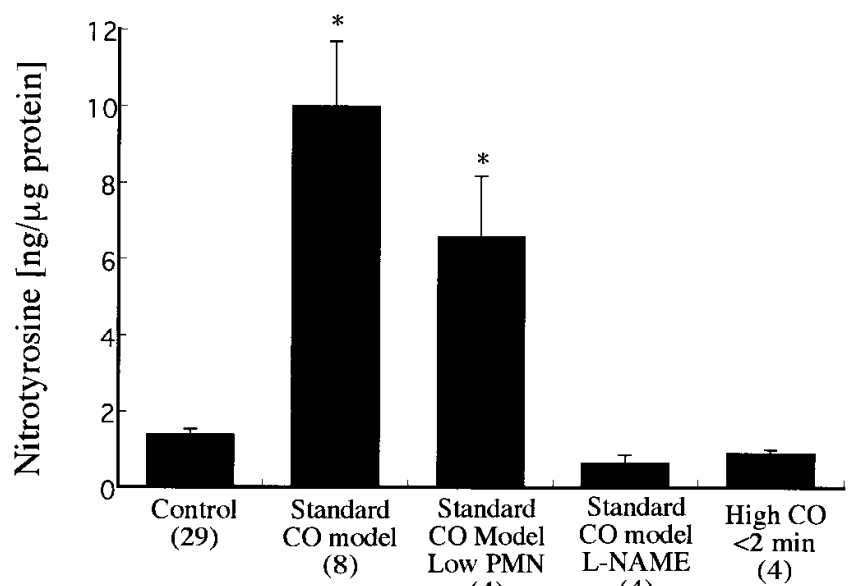

(4)

(4)

Figure 5. Nitrotyrosine concentration in rat brain homogenates. Rats were exposed to the standard CO model or to a bolus of CO to cause unconsciousness in $<2 \mathrm{~min}$, as described in Methods. L-NAME (1 $\mathrm{mg} / \mathrm{kg}$ i.p.) was injected $2 \mathrm{~h}$ before $\mathrm{CO}$ poisoning. Neutropenic rats had fewer than 200 polymorphonuclear leukocytes/ $\mu$ l blood. $(n)=$ number of rats; * significantly greater than control.

Effect of platelets on nitrotyrosine formation. Based on the immunocytochemical findings and the quantitative results summarized in Fig. 5, we hypothesized that a perivascular oxidative stress may be an early event during $\mathrm{CO}$ poisoning. Therefore, we examined whether exposure to $\mathrm{CO}$ at $1000 \mathrm{ppm}$, the first portion of the standard $\mathrm{CO}$ model, led to nitrotyrosine formation. We found the nitrotyrosine concentration to be significantly increased in brains of rats exposed to $1000 \mathrm{ppm} \mathrm{CO}$ for $40 \mathrm{~min}$ (Fig. 6). Moreover, when the number of circulating platelets was decreased to $15.6 \pm 8 \%(n=6)$ of the control level by injecting rats with anti-platelet antiserum (see Methods), no significant increase in nitrotyrosine was observed.

When the length of exposure to $1000 \mathrm{ppm} \mathrm{CO}$ was increased to $60 \mathrm{~min}$, the nitrotyrosine concentration in brain was significantly higher than after $40 \mathrm{~min}$, and the concentration of nitrotyrosine was actually higher in rats with low numbers of platelets (Fig. 6). Hence, mechanisms unrelated to platelet-derived oxidants must cause nitrotyrosine formation during the hourlong exposures. In this situation, platelets appear to antagonize the oxidative process; a phenomenon reported in several models of oxidative stress $(24,25)$. The concentration of nitrotyrosine was the same whether rats were exposed to $1000 \mathrm{ppm}$ $\mathrm{CO}$ for $1 \mathrm{~h}$ or to the full, standard $\mathrm{CO}$ model which involved exposure to $1000 \mathrm{ppm}$ for $40 \mathrm{~min}$ and then to $3000 \mathrm{ppm}$ for $20 \mathrm{~min}$ (Fig. 5). Thrombocytopenic rats exposed to the standard CO model exhibited nearly the same increase in nitrotyrosine as did rats with normal platelet counts, $13.9 \pm 6.0 \mathrm{ng}$ nitrotyrosine $/ \mu \mathrm{g}$ protein $(n=5)$.

Role of platelets and nitric oxide in leukocyte sequestration. In previous studies we found that $\mathrm{CO}$ poisoning caused leukocyte sequestration in brain microvessels, and we measured this effect as an increase in myeloperoxidase activity (7). In a new series of studies (Table I) we found a sixfold increase in myeloperoxidase activity in microvessels from $\mathrm{CO}$ poisoned rats, and no significant difference in thrombocytopenic rats poisoned with CO. However, treatment with L-NAME $(1 \mathrm{mg} / \mathrm{kg}$ i.p. $2 \mathrm{~h}$ before $\mathrm{CO}$ poisoning) inhibited leukocyte sequestration.

Role of nitric oxide in biochemical indices of $\mathrm{CO}$-mediated brain oxidative stress. The results of previous studies indicate 


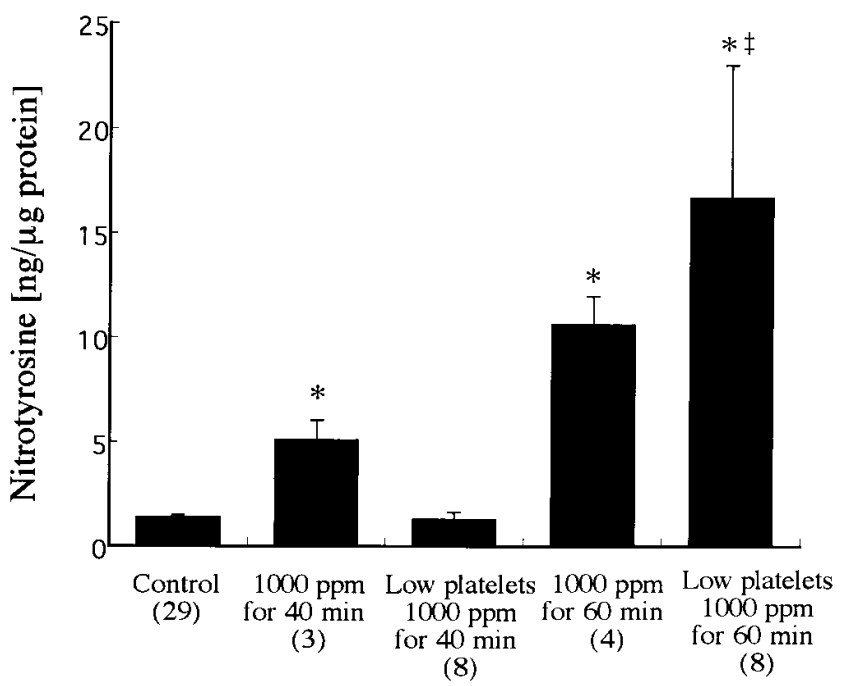

Figure 6. Nitrotyrosine concentration in rat brain homogenates. Rats were exposed to $1000 \mathrm{ppm} \mathrm{CO}$ for $40 \mathrm{~min}$ or $1 \mathrm{~h}$. Circulating platelets were decreased by injecting anti-platelet antiserum $2 \mathrm{~h}$ before $\mathrm{CO}$ exposure. $(n)=$ number of rats, ${ }^{*} P<0.05$ significantly greater than control ${ }^{\ddagger} P<0.01$ significantly greater than value for rats exposed to $1000 \mathrm{ppm} \mathrm{CO}$ for $1 \mathrm{~h}$

that following their sequestration in the brain microvasculature, leukocytes become activated and cause endothelial xanthine dehydrogenase to be converted to xanthine oxidase (7). Xanthine oxidase activity is responsible for causing brain lipid peroxidation $(7,9)$. We were therefore interested in assessing the effect of L-NAME treatment on these indices, as it appeared effective in inhibiting leukocyte sequestration. As shown in Table II, L-NAME was effective in preventing CO-mediated biochemical effects. $\mathrm{CO}$ poisoning caused xanthine oxidase activity to increase to $51 \%$ of the total dehydrogenase plus oxidase activity, virtually all of the increase was due to a change in the sulfhydryl-irreversible form, and the brain conjugated diene level was increased 2.5-fold. The brains of rats treated with L-NAME did not show these changes.

\section{Discussion}

The results of this study provide information on early oxidative changes that occur in brain following $\mathrm{CO}$ poisoning. A burst of NO- was detected in brain at the termination of $\mathrm{CO}$ exposure when unconsciousness occurred. We have shown that unconsciousness is associated with cerebral hypoperfusion, and that blood flow is decreased to $\sim 50 \%$ of control for several minutes $(8,10)$. It is likely that this vascular stress contributed to the production of $\mathrm{NO}$, as the concentration of $\mathrm{NO}$. in brain has been found to increase in response to a reduction in blood pressure (20).

The immunohistochemical studies indicated that nitrotyrosine was deposited predominantly in the perivascular region. This suggested that the vascular endothelium and/or bloodborne elements may be responsible for generation of oxidants. We developed a solid phase immunoradiochemical assay to quantify nitrotyrosine in tissue using polyclonal anti-nitrotyrosine antibodies. Using this method we found a marked rise in nitrotyrosine in brains of rats exposed to CO. Neutrophils did not appear to be involved in nitrotyrosine formation, based
Table I. Myeloperoxidase Activity in Brain Microvessels from Rats Killed Immediately after CO Poisoning

\begin{tabular}{lcc}
\hline \multicolumn{1}{c}{ Group } & $n$ & Enzyme Activity \\
\hline Control & 4 & $2.6 \pm 0.4$ \\
CO & 5 & $13.0 \pm 3.3^{*}$ \\
CO (Low plts) & 3 & $11.7 \pm 2.3^{*}$ \\
CO + L-NAME & 5 & $2.3 \pm 0.7$ \\
\hline
\end{tabular}

Values are mean \pm SE. Myeloperoxidase activity was expressed as absorbance at $460 \mathrm{~nm}\left(\mathrm{~A}_{460}\right) \times 1000 /$ min per gram brain. Thrombocytopenia (low plts) was induced with anti-platelet antibodies as described in Methods. $* P<0.05$ relative to control, $n=$ number of rats.

on the results with neutropenic rats. We investigated the involvement of neutrophils because these cells can generate both superoxide and nitric oxide $(26,27)$, and we have shown that neutrophils are involved with conversion of xanthine dehydrogenase to xanthine oxidase (7).

Based on findings with thrombocytopenic rats, platelets were one source of oxidants responsible for nitrotyrosine formation when animals were exposed to $1000 \mathrm{ppm} \mathrm{CO}$ for $40 \mathrm{~min}$. However, there does not appear to be a large role for platelets in brain oxidative stress associated with the standard $\mathrm{CO}$ model. Nitrotyrosine levels in brain were not significantly different in thrombocytopenic rats poisoned with $\mathrm{CO}$ and leukocyte adherence to microvessels, which was assessed as myeloperoxidase activity, was not changed. Cells intrinsic to the brain, such as neurons and the microvascular endothelium, are possible alternative sources for oxidants that generate nitrotyrosine. However, it is intriguing to consider a possible role for platelets in $\mathrm{CO}$ exposures that do not result in overt brain injuries. Although controversial, some epidemiological studies have suggested that exposure to $\mathrm{CO}$ can accelerate atherosclerosis (28). Superoxide and peroxynitrite may be mediators of atherosclerosis, and nitrotyrosine deposits have been found in atherosclerotic fatty streaks $(14,29)$.

The data suggest that oxidative stress mediated by peroxynitrite, or other NO--related oxidants, may be required for the cascade of events which lead to brain lipid peroxidation in $\mathrm{CO}$ poisoning. Oxidative stress is known to cause expression of adherence molecules for leukocytes on endothelial cells (30). It is also feasible that NO-related oxidants may cause generation of other pro-adhesive substances, such as platelet activating factor (31). We hypothesize that NO-related oxidative

Table II. Xanthine Dehydrogenase, Xanthine Oxidase, and Conjugated Diene Levels in Brain Homogenates from Rats Killed 90 min after CO Poisoning

\begin{tabular}{llllll}
\hline \multicolumn{1}{c}{ Group } & $n$ & $\mathrm{XD}+\mathrm{XO}$ & \multicolumn{1}{c}{ Total XO } & \multicolumn{1}{c}{ Irreversible } \\
\hline Control & 6 & $0.95 \pm 0.17$ & $0.21 \pm 0.05$ & $0.14 \pm 0.04$ & \multicolumn{1}{c}{ CD } \\
CO & 6 & $0.97 \pm 0.11$ & $0.49 \pm 0.11^{*}$ & $0.38 \pm 0.05^{*}$ & $6.2 \pm 0.8^{*}$ \\
CO + L-NAME & 4 & $1.04 \pm 0.12$ & $0.14 \pm 0.02$ & $0.09 \pm 0.01$ & $2.1 \pm 0.3$
\end{tabular}

Values are mean \pm SE. Enzyme activity was expressed as $\mathrm{mU} / \mathrm{mg}$ protein; conjugated diene level was expressed as $\mu \mathrm{mol} / \mathrm{mg}$ lipid. $X D$, xanthine dehydrogenase; $X O$, xanthine oxidase; $C D$, conjugated diene. $* P<$ 0.05 relative to control, $n=$ number of rats. 
stress causes expression of adherence molecules on endothelial cells, and that leukocytes bind to these substances when cerebral blood flow decreases during exposure to $3000 \mathrm{ppm}$ CO in the standard model. This hypothesis is supported by two observations. We have found that exposure to $1000 \mathrm{ppm} \mathrm{CO}$ for 40 min will generate perivascular nitrotyrosine, but brief exposures to high concentrations of $\mathrm{CO}$ will not cause significant formation of nitrotyrosine. In previous studies we found that when rats were exposed to $\mathrm{CO}$ in a pattern reversed from the standard model, a high concentration of $\mathrm{CO}$ to cause unconsciousness and then $1000 \mathrm{ppm} \mathrm{CO}$ for $40 \mathrm{~min}$, conversion of xanthine dehydrogenase to xanthine oxidase and lipid peroxidation did not occur $(8,9)$. Hence, cerebral hypoperfusion occurred before the development of vascular oxidative changes. The second observation is based on work with L-NAME. Injections of L-NAME prevented perivascular nitrotyrosine deposition, as well as all subsequent steps linked with brain lipid peroxidation: leukocyte sequestration, conversion of xanthine dehydrogenase to xanthine oxidase, and lipid peroxidation. These results do not contradict reports which show that $\mathrm{NO} \cdot$ can inhibit leukocyte $\mathrm{B}_{2}$ integrin adherence $(32,33)$. It is important to keep in mind the temporal pattern of events with $\mathrm{CO}$ poisoning. Vascular changes, such as nitrotyrosine deposition, precede leukocyte sequestration that initially does not appear to depend on $\mathrm{B}_{2}$ integrins (7). Indeed, we have shown that the high flux of $\mathrm{NO}$ - from platelets in the first $45 \mathrm{~min}$ after poisoning inhibits the function of leukocyte $\mathrm{B}_{2}$ integrins (5).

Further work is necessary to elucidate the agents responsible for leukocyte adherence, and to clarify the consequences of brain lipid peroxidation. This work may lead to a better understanding of $\mathrm{CO}$ poisoning as a reperfusion-like injury, and greater insight into possible treatments. The presence of nitrotyrosine in the brain microvasculature is indicative of production of a NO-related oxidant, but it is not synonymous with peroxynitrite. Hence, the direct contribution of peroxynitrite to CO-related neuropathology remains unknown. It is interesting to note, however, that peroxynitrite can inhibit DOPA synthesis (34). Excessive neuronal production of an NO-derived oxidant appears responsible for the neurotoxicity associated with $N$-methyl-D-aspartate receptor activation (35), and inhibitors of receptor activation have been shown to decrease neurotoxicity in one model of CO poisoning (36).

\section{Acknowledgment}

We are grateful to Drs. J.S. Beckman and Y.Z. Ye for providing the anti-nitrotyrosine antibody, Dr. Horace Delisser for providing the anti-CD31 antibody, Dr. Henry Shuman and Kathleen Notarfrancesco for advice and assistance with the immunohistology, and Dr. Tomoko Ohnishi for the use of the EPR instrument.

This work was supported by grants from the National Institutes of Health ES-05211 (S.R. Thom) and NS 30186 (S.T. Ohnishi), from the Council for Tobacco Research (S.R. Thom), from the Pennsylvania Lung and Southeastern Pennsylvania Heart Associations (H. Ischiropoulos). Dr. Beers is a recipient of a clinical-scientist award from the American Heart Association. Dr. Ischiropoulos is a Parker B. Francis Fellow in Pulmonary Research.

\section{References}

1. Beckman, J.S., T.W. Beckman, J. Chen, P.A. Marshall, and B.A. Freeman. 1990. Apparent hydroxyl radical production by peroxynitrite: Implications for endothelial injury from nitric oxide and superoxide. Proc. Natl. Acad. Sci. USA. 87:1620-1624.
2. Huie, R.E., and S. Padjama. 1993. The reaction of NO with superoxide. Free Rad. Res. Comm. 18:195-199.

3. Bianco, F., and R. Floris. 1988. Transient disappearance of bilateral lowdensity lesions of the globus pallidus in carbon monoxide intoxication and MRI. J. Neuroradiol. 15:381-385.

4. Silverman, C.S., J. Brenner, and F.R. Murtagh. 1993. Hemorrhagic necrosis and vascular injury in carbon monoxide poisoning. MR demonstration. Am. J. Neuroradial. 14:168-170.

5. Thom, S.R., S.T. Ohnishi, and H. Ischiropoulos. 1994. Nitric oxide released by platelets inhibits neutrophil $\mathrm{B}_{2}$ integrin function following acute carbon monoxide poisoning. Toxicol. Appl. Pharmacol. 128:105-110.

6. Zhang, J., and C.A. Piantadosi. 1991. Mitochondrial oxidative stress after carbon monoxide hypoxia in the rat brain. J. Clin. Invest. 90:1193-1199.

7. Thom, S.R. 1993. Leukocytes in carbon monoxide-mediated brain oxidative injury. Toxicol. Appl. Pharmacol. 123:234-247.

8. Thom, S.R. 1990. Carbon monoxide-mediated brain lipid peroxidation in the rat. J. Appl. Physiol. 68:997-1003.

9. Thom, S.R. 1992. Dehydrogenase conversion to oxidase and lipid peroxidation in brain after carbon monoxide poisoning. J. Appl. Physiol. 73:15811589 .

10. Mayevsky, A., S. Meilin, G.G. Rogatsky, N. Zarchin, and S.R. Thom 1995. Multiparametric monitoring of the awake brain exposed to carbon monoxide. J. Appl. Physiol. 78:1188-1196.

11. Beckman, J.S., J. Chen, H. Ischiropoulos, and J.P. Crow. 1994. Oxidative chemistry of peroxynitrite. Methods Enzymol. 233:229-240.

12. Radi, R., J.S. Beckman, K.M. Bush, and B.A. Freeman. 1991. Peroxynitrite oxidation of sulfhydryls. The cytotoxic potential of superoxide and nitric oxide. J. Biol. Chem. 266:4244-4250.

13. Ischiropoulos, H., L. Zhu, J. Chen, M. Tsai, J.C. Martin, C.D. Smith, and J.S. Beckman. 1992. Peroxynitrite-mediated tyrosine nitration catalyzed by superoxide dismutase. Arch. Biochem. Biophys. 298:431-437.

14. Beckman, J.S., Y.Z. Ye, P. Anderson, J. Chen, M.A. Accavitti, M.M. Tarpey, and C.R. White. 1994. Extensive nitration of protein tyrosines in human atherosclerosis detected by immunohistochemistry. Biol. Chem. HoppeSeyler. 375:81-88.

15. Haddad, I.Y., G. Pataki, P. Hu, J.S. Beckman, and S. Matalon. 1994. Quantification of nitrotyrosine levels in lung sections of patients and animals with acute lung injury. J. Clin. Invest. 94:2407-2413.

16. Kooy, N.W., J.A. Royall, Y.Z. Ye, D.R. Kelly, and J.S. Beckman. 1995. Evidence for in vivo peroxynitrite production in human acute lung injury. Am. J. Resp. Crit. Care Med. 151:1250-1254.

17. Wizemann, T.M., C.R. Gardner, J.D. Laskin, S. Quinones, K.D. Durham, N.L. Golle, S.T. Ohnishi, and D.L. Laskin. 1994. Production of nitric oxide and peroxynitrite in the lung during acute endotoxemia. J. Leuk. Biol. 56: 759-768.

18. Szabo, C., A.L. Salzman, and H. Ischiropoulos. 1995. Endotoxin triggers the expression of an inducible isoform of nitric oxide synthase in the rat aorta in vivo. FEBS Lett. 363:235-238

19. Sato, S., T. Tominaga, T. Ohnishi, and S.T. Ohnishi. 1994. Electron paramagnetic resonance study on nitric oxide production during brain focal ischemia and reperfusion in the rat. Brain Res. 647:91-96.

20. Tominaga, T., S. Sato, T. Ohnishi, and S.T. Ohnishi. 1994. Electron paramagnetic resonance (EPR) detection of nitric oxide produced during forebrain ischemia of the rat. J. Cereb. Blood Flow Metab. 14:715-722.

21. Hogg, N., V.M. Usmar-Darley, M.T. Wilson, and S. Moncada. 1992. Production of hydroxyl radicals from the simultaneous generation of superoxide and nitric oxide. Biochem. J. 281:419-424.

22. Snedecor, G.W., and W.G. Cochran. 1980. Statistical Methods. Iowa State University Press, Ames, Iowa.

23. Vaporciyan, A.A., H.M. DeLisser, H.C. Yan, I.I. Mendiguren, S.R. Thom, M.L. Jones, P.A. Ward, and S.M. Albelda. 1993. Involvement of platelet-endothelial cell adhesion molecule-1 in neutrophil recruitment in vivo. Science (Wash. DC). 262:1580-1582.

24. Zamora, C.A., D. Baron, and J. Heffner. 1991. Washed human platelets prevent ischemia-reperfusion edema in isolated rabbit lungs. J. Appl. Physiol. 70:1075-1084

25. Heffner, J.E., S.A. Katz, P.V. Halushka, and J.A. Cook. 1988. Human platelets attenuate oxidant injury in isolated rabbit lungs. J. Appl. Physiol. 65: 1258-1266.

26. Carreras, M.C., G.A. Pargament, S.D. Catz, J.J. Poderoso, and A. Boveris. 1994. Kinetics of nitric oxide and hydrogen peroxide production and formation of peroxynitrite during the respiratory burst of human neutrophils. FEBS Lett. 341:65-68.

27. Rodenas, J., M.T. Mitjavila, and T. Carbonell. 1995. Simultaneous generation of nitric oxide and superoxide by inflammatory cells in rats. Free Rad. Biol. Med. 18:869-875.

28. Stern, F.B., W.E. Halperin, R.W. Hornung, V.L. Ringenburg, and C.S McCammon. 1988. Heart disease mortality among bridge and tunnel officers exposed to carbon monoxide. Am. J. Epidemiol. 128:1276-1288.

29. White, C.R., T.A. Brock, L-Y. Chang, J. Crapo, P. Briscoe, D. Ku, W.A. Bradley, S.H. Gianturco, J. Gore, B.A. Freeman, and M.M. Tarpey. 1994 Superoxide and peroxynitrite in atherosclerosis. Proc. Natl. Acad. Sci. USA. 91: 1044-1048. 
30. Patel, K.D., G.A. Zimmerman, S.M. Prescott, R.P. McEver, and T.M. McIntyre. 1991. Oxygen radicals induce human endothelial cells to express GMP-140 and bind neutrophils. J. Cell Biol. 112:749-759.

31. Zimmerman, G.A., T.M. McIntyre, M. Mehra, and S.M. Prescott. 1990. Endothelial cell-associated platelet-activating factor: a novel mechanism for signaling intercellular adhesion. J. Cell Biol. 110:529-540.

32. McCall, T., B.J.R. Whittle, N.K. Boughton-Smith, and S. Moncada. 1988. Inhibition of FMLP-induced aggregation of rabbit neutrophils by nitric oxide. Br. J. Pharmacol. 95:517P (abstr.).

33. Bath, P.M.W., D.G. Hassall, A.M. Gladwin, R.M.J. Palmer, and J.F. Martin. 1991. Nitric oxide and prostacyclin: Divergence of inhibitory effects on monocyte chemotaxis and adhesion to endothelium in vitro. Arterioscler.
Thromb. 11:254-260.

34. Ischiropoulos, H., D. Duran, and J. Horwitz. 1995. Peroxynitrite-mediated inhibition of DOPA synthesis in PC12 cells. J. Neurochem. 65:2366-2372.

35. Lipton, S.A., Y.-B. Choi, Z.-H. Pan, S.Z. Lei, H.-S. Chen, N.J. Sucher, J. Loscalzo, D.J. Singel, and J.S. Stamler. 1993. A redox-based mechanism for the neuroprotective and neurodestructive effects of nitric oxide and related nitroso-compounds. Nature (Lond.). 364:626-632.

36. Ishimaru, H., A. Katoh, H. Suzuki, T. Fukuta, T. Kameyama, and T. Nabeshima. 1992. Effects of $N$-methyl-D-aspartate receptor antagonists on carbon monoxide-induced brain damage in mice. J. Pharmacol. Exp. Therap. 261: 349-352. 